\title{
Implementation in Buenos Aires City of a program to prevent neurological damage caused by hypoxic-ischemic encephalopathy. Therapeutic hypothermia
}

\author{
Mariana Valera, M.D. ${ }^{a}$, Juan Pablo Berazategui, M.D. ${ }^{a}$, Gladys Saa, M.D. ${ }^{a}$, Carolina Olmo Herrera, M.D. ${ }^{a}$, \\ Teresa Sepúlveda, M.D. ${ }^{a}$, María Fernanda Buraschi, M.D. ${ }^{a}$, Sebastián Gacio, M.D.,b Cristina Villalba, B.S. ${ }^{a}$, \\ Inés Beloso, B.S. ${ }^{c}$, Graciela Basso, M.D. ${ }^{a}$, Waldemar Carlo, M.D. ${ }^{d}$, and Jorge Tavosnanska, M.D. ${ }^{a}$
}

\begin{abstract}
Therapeutic hypothermia is the standard of care for hypoxic-ischemic encephalopathy (HIE). This treatment was implemented at a regional level by the perinatal network of the City of Buenos Aires. The following are the objectives of this article: 1 . To describe the implementation of the network's hypothermia treatment program; 2 . To report treatmentassociated complications, adverse events and mortality.

The program was implemented in stages: 1) 2009-2010. Training and instruction on how to use the equipment. 2) 20102014. Treatment and follow-up of patients with moderate or severe HIE. Up to October 2014, 27 newborn infants received hypothermia treatment with moderate $(n=15)$ and severe $(n=12)$ HIE. None of the patients died during treatment. Threenewborn infants were lost to follow-up. Among the 16 survivors older than one year old, three have severe neurological disability. Program implementation was plausible. It is imperative to train health care providers on how to identify patients with HIE. Key words: newborn infant, hypoxic-ischemic encephalopathy, therapeutic hypothermia.
\end{abstract}

http:/ /dx.doi.org/10.5546/aap.2015.eng.438

\section{INTRODUCTION}

Therapeutic hypothermia (TH) for neonatal hypoxic-ischemic encephalopathy (HIE) is the standard of care in the developed world.

a. Division of Neonatology.

b. Department of Pediatrics.

c. Department of Speech Therapy.

Hospital General de Agudos "Juan A. Fernández" (HGAJAF), Autonomous City of Buenos Aires, Argentina.

d. Division of Neonatology, University of Alabama, USA.

E-mail Address:

Jorge Tavosnanska, M.D.: jtavos@intramed.net

Funding: None.

Conflict of Interest: The Division of Neonatology of Hospital General de Agudos "Juan A. Fernández" received the Cool Cap ${ }^{\circledast}$ equipment from Medix $^{\circledast}$ by Natus ${ }^{\circledR}$ for selective hypothermia, and the Amrra-Term ${ }^{\circledast}$ equipment for wholebody hypothermia, and the CFM Olympic $6000^{\circledR}$ equipment from Medix ${ }^{\circledast}$ by Natus ${ }^{\circledast}$ for brain function monitoring.

Received: 12-14-2014

Accepted: 3-30-2015
Several clinical trials have demonstrated that reducing brain temperature by $3-4{ }^{\circ} \mathrm{C}$ through whole-body or selective hypothermia results in an effective and safe intervention to reduce mortality and major disabilities among survivors. ${ }^{1-3}$ Cooling is started before six hours of life and is maintained for 72 hours, followed by gradual rewarming. Hypothermia appears to stop several biochemical cascades that cause damage in this phase: reduction of brain metabolism (secondary energy failure), suppression of apoptotic cell death, inflammatory response and microglial activation..$^{4-8}$ The extended duration of its therapeutic window and its synergestic effect with other neuroprotective strategies add to its potential clinical use. ${ }^{9}$

Safety and effectiveness observed in clinical trials have been confirmed by, at least, four metaanalysis (Edwards, et al, ${ }^{9}$ Schulzke, et al, ${ }^{10}$ Shah, et $\mathrm{al}^{11}$ and Jacobs, et al). ${ }^{12}$

Providing this intervention at the perinatal network of the City of Buenos Aires, where the birth rate reaches 30,000 births per year, requires an effective coordination within the health system. We decided to establish a program that offers hypothermia treatment to newborn infants (NBIs) with HIE born within the network. As in other regions around the world, we propose this strategy in the context of a regionalized perinatal system. To this end, we executed an agreement and established emergency criteria with the Buenos Aires public emergency ambulance service (Sistema de Atención Médica de Emergencias, SAME) for the timely referral and transfer of patients.

\section{OBJECTIVES}

1. To describe the implementation process of the hypothermia treatment program within the perinatal network of the Autonomous City of Buenos Aires (CABA).

2. To report treatment-associated complications, adverse events, and mortality. 


\section{THE PROTOCOL}

Its implementation was carried out in two stages.

First stage (June 2009-June 2010):

Design of a strategy to implement therapy

1. Creation of a work group.

2. Selection of the protocol to be implemented.

3. Review of all steps in neonatal care, from the delivery room to the reception at the neonatal intensive care unit (NICU), to ensure compliance with the regulations of the Neonatal Resuscitation Program of the Argentine Society of Pediatrics in place in $2011 ; 100 \%$ of staff members were trained on such regulations.

4. Instruction of all NICU health care providers through training provided to physicians and nurses working on different shifts, on how to implement the "new" protocol (clinical case simulation, use of hypothermia equipment and brain function monitoring, controls to be made and filling in corresponding forms).

5. Training of all heads of the Departments of Neonatology that participate in the newtork on how the program works.

6. Briefings were conducted at the 12 maternity centers participating in the network on the program, inclusion criteria, communication channels, and activation of the SAME neonatal transfer system.

7. Establishing a hypothermia code for SAME for the timely referral and transfer of patients.

8. Agreement executed with SAME regarding the cooling process and controls to be performed during transfer so that core temperature is adequately maintained and temperature fluctuations are avoided.

9. Inclusion of a pediatric neurologist in the Department of Neonatology to be part of the work group and provide follow-up.

10. Establishing rules for patient follow-up.

\section{Second stage (July 2010-October 2014):}

Implementation of the hypothermia protocol

1. Therapy implementation.

2. Database creation.

3. Development of a specific follow-up program to assess neurological development outcomes (Bayley III scales).

4. Work group meetings to reassess the program, objective compliance, and quality improvements (process internal audits).

5. Introduction of new equipment (following authorization by the Drug, Food and Technology Administration of Argentina
[ANMAT], we included the national Amrra-Term ${ }^{\circledR}$ equipment for whole-body hypothermia in addition to the Cool Cap ${ }^{\circledR}$ equipment already used for selective hypothermia).

6. Review of present bibliography on new adjuvant therapies.

\section{Inclusion criteria for protocol entry}

1. NBI with a gestational age (GA) $\geq 36$ weeks and a birth weight $(B W) \geq 1800$ grams with moderate or severe HIE (Sarnat \& Sarnat).

2. Apgar score $\leq 5$ at 10 minutes.

3. Umbilical cord $\mathrm{pH}$ and/or $\mathrm{pH}$ in the first hour of life $\leq 7$ and/or base deficit $\geq-16$.

4. Presence of a sentinel hypoxic event (for example, abruptio placentae).

5. Ventilation requirement $\geq 10$ minutes.

6. If transferred to our facility, parents were asked to sign an informed consent form so that patients were admitted to the protocol.

7. Following transfer request, being able to arrive at Hospital Fernández before 6 hours of life with continuous monitoring of core temperature. If active treatment was started with inadequate equipment, the possibility of admission was considered between 6 and 12 hours of life.

\section{Exclusion criteria}

1. Patients with mild encephalopathy.

2. Patients who could not be transferred due to their severe condition (joint assessment by a SAME physician).

3. Not being able to arrive at the NICU before 6 hours of life with no active treatment.

\section{Clinical experience}

Due to the low prevalence of hypoxicischemic encephalopathy and its higher incidence in primary and secondary care facilities, we estimated that more than half of eligible infants would be referred to our hospital (Figure 1). Although the total number was much lower in the period described, the proportion adding our own patients and those referred was as expected. Once the informed consent was signed, patients were transferred, but we are not aware of how many parents refused signing the consent to transfer their children to a tertiary care facility. The reason for refusing admission to our division was noncompliance with inclusion criteria; $93 \%$ of referral requests were accepted.

In relation to treatment offered to patients with whole-body hypothermia $(\mathrm{WBH})$ or selective 
hypothermia $(\mathrm{SH})$, it is worth noting that the $\mathrm{SH}$ equipment was the first one approved by ANMAT to be used as treatment for HIE and, for this reason, early patients were treated with this equipment. Then two pieces of WBH equipment were approved, one imported and one of national origin, both servo-controlled. Systematic reviews published to date have found no statistically significant differences in terms of the main outcome of compared studies, therefore, at present, we offer one or other equipment depending on their availability. ${ }^{11}$ There have been no complications nor differences in results obtained with both pieces of equipment together with brain function monitoring using the CFM Olympic $6000^{\circledR}$ device.

The frequency of sentinel events and treatment-associated complications were similar to those reported at an international level. No infant died during treatment or due to treatmentrelated complications (Tables 1 and 2), but three (11\%) died before one month old.

A brain magnetic resonance imaging was performed in 20 out of 27 patients between 5 and 20 days of life, six MRIs were found to be pathological.

Three patients were lost to follow-up and five are still younger than one year old. Among the 16 survivors older than one year old, three have severe neurological disability and one has a genetic syndrome under study (Figure 2).

\section{COMMENT}

At present, the possibility of preventing or reducing HIE-associated brain damage through sustained moderate hypothermia has resulted in the establishment of specific health care programs.

Based on our experience, it was plausible to implement a hypothermia treatment program. Treatment-associated complications, mortality and morbidity were similar to those published internationally.

Given that hypothermia treatment appears to be effective when started before six hours of life, it is necessary: a) to concentrate programs in several tertiary care facilities by geographic area; and b) to establish a "hypothermia code" to ensure the immediate and safe transfer of patients from the original facility to the referral center. For such code to be useful, it is necessary for all parties involved to be coordinated in an adequate operational manner. ${ }^{13}$

Although so far we do not have accurate rates regarding the prevalence of children born with HIE, both at a national level and at the City of Buenos Aires network, we estimate that the number of infants referred for neuroprotective management was much lower than expected, so we believe that a tool should be implemented to be able to train staff members and have a greater impact on the maternity centers participating in the network of the City of Buenos Aires in order to increase the number of referrals and achieve treatment equity.

\section{REFERENCES}

1. Gluckman PD, Wyatt JS, Azzopardi D, Ballard R, et al Selective head cooling with mild systemic hypothermia after neonatal encephalopathy: multicentre randomized trial. Lancet 2005;365(9460):663-70.

FIGURE 1. Flow chart of selection and follow-up of patients who received hypothermia treatment

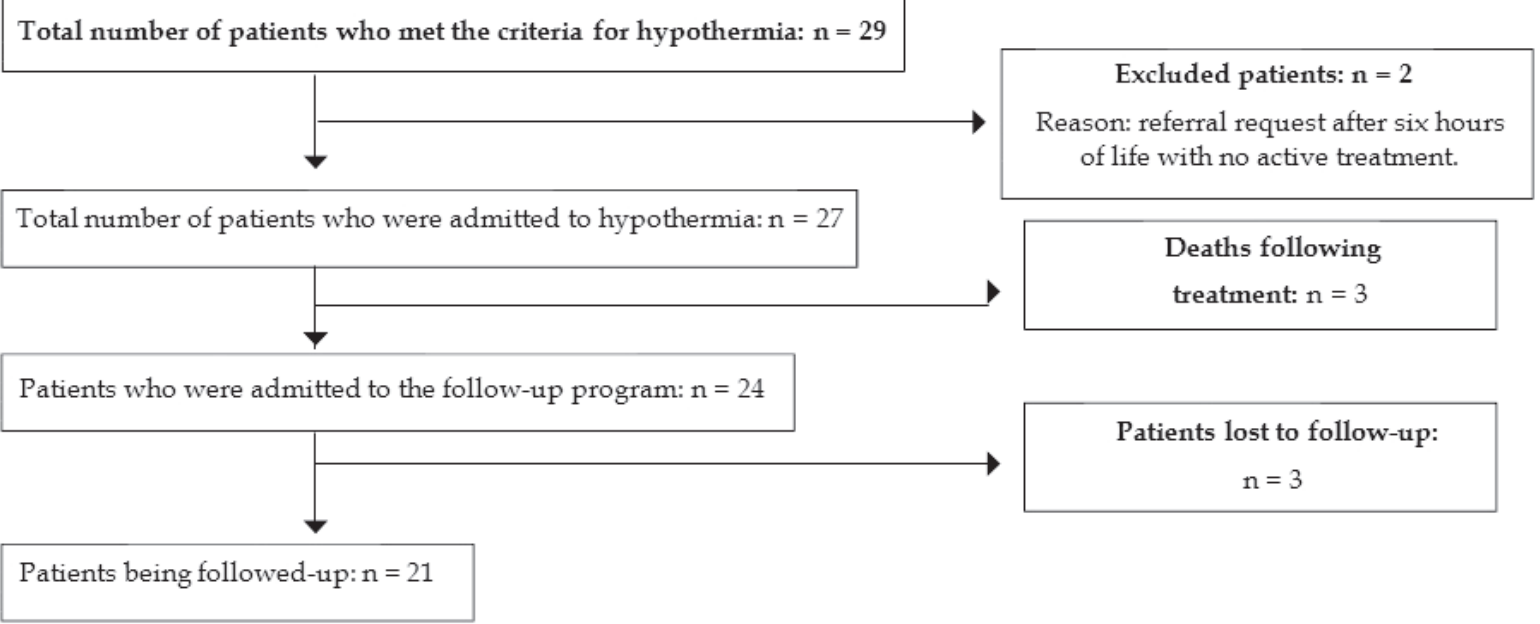


440 / Arch Argent Pediatr 2015;113(5):437-442 / Brief report

Table 1. Characteristics of patients admitted to the hypothermia treatment protocol

\begin{tabular}{|c|c|c|}
\hline Perinatal and resuscitation variables & $\begin{array}{c}\mathrm{n}=27 \\
\text { Mean (SD) }\end{array}$ & n $(\%)$ \\
\hline Weight & $3281.11 \mathrm{~g}(724.4)$ & \\
\hline Gestational age & 39.03 weeks (1.5) & \\
\hline Vaginal & & $15(55.5)$ \\
\hline Forceps & & $1(3.7)$ \\
\hline C-section & & $11(40.7)$ \\
\hline Perinatal history - fetal bradychardia & & $11(40.7)$ \\
\hline Perinatal history - prolonged second stage of labor & & $8(29.6)$ \\
\hline Perinatal history - abruptio placentae & & $4(14.8)$ \\
\hline Perinatal history - fetal tachycardia & & $1(3.7)$ \\
\hline Perinatal history - umbilical cord prolapse & & $2(7.4)$ \\
\hline Perinatal history - umbilical cord entanglement & & $2(7.4)$ \\
\hline Meconium staining of the amniotic fluid & & $9(33.3)$ \\
\hline Breech presentation & & $1(7.1)$ \\
\hline Apgar at 1 minute $\leq 5$ & & $14(100)$ \\
\hline Apgar at 5 minutes $\leq 5$ & & $8(57.1)$ \\
\hline Only PPV & & $9(33.3)$ \\
\hline PPV + ETI & & $7(25.9)$ \\
\hline PPV + ETI + heart massage & & $7(25.9)$ \\
\hline PPV + ETI + heart massage + drugs & & $4(14.8)$ \\
\hline Selective hypothermia & & $21(77.7)$ \\
\hline Whole-body hypothermia & & $6(22.2)$ \\
\hline Time of admission to hypothermia (hours) & $4.07(1.9)$ & \\
\hline Temperature upon admission & $34.65(0.7)$ & \\
\hline Umbilical cord $\mathrm{pH}$ or $\mathrm{pH}$ in the first hour of life & $6.88(0.2)$ & \\
\hline Base excess & $-18.3(5.4)$ & \\
\hline
\end{tabular}

PPV: positive pressure ventilation; ETI: endotracheal intubation.

TABLE 2. Associated complications during hypothermia treatment

\begin{tabular}{lc}
\hline Hypothermia-associated complications & $\mathbf{n = 2 7 ( \% )}$ \\
\hline None & $12(44.44)$ \\
Bradycardia & $2(7.40)$ \\
Hypotension & $2(7.40)$ \\
Alterations in coagulation profile & $10(37.03)$ \\
Thrombocytopenia & $4(14.81)$ \\
\hline
\end{tabular}

Figure 2. Bayley III test at one year old

$\mathrm{n}=13$

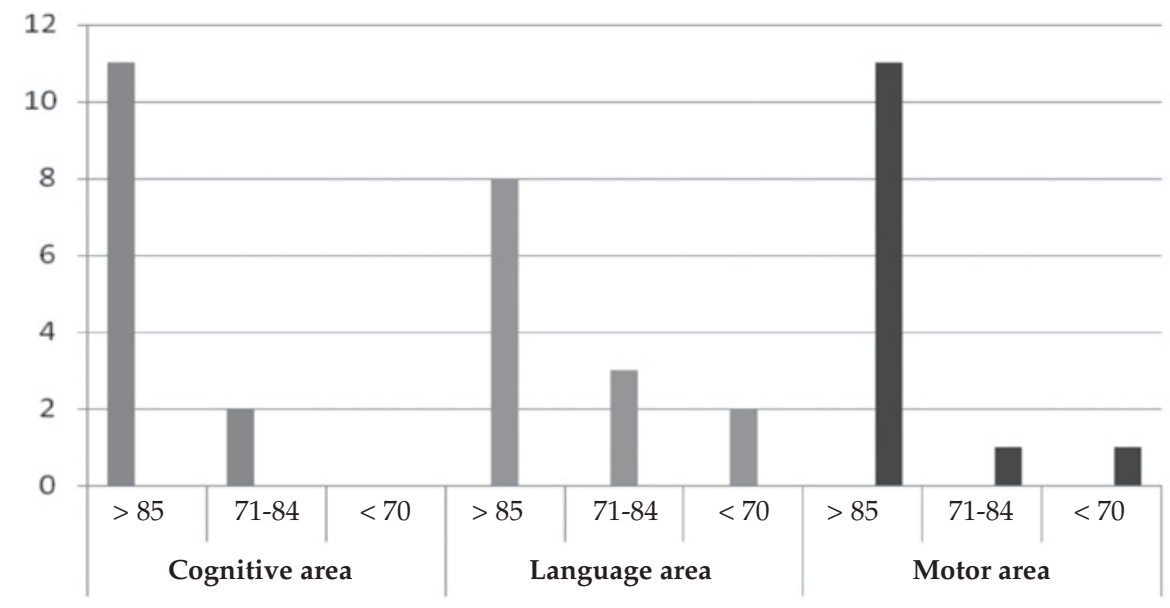


2. Shankaran S, Laptook AR, Ehrenkranz RA, Tyson JE, et al Whole-body hypothermia for neonates with hypoxic-ischemic encephalopathy. New Engl J Med 2005;353(15):1574-84.

3. Azzopardi DV, Strohm B, Edwards AD, Dyet L, et al Moderate hypothermia to treat perinatal asphyxia encephalopathy. N Engl J Med 2009;361(14):1349-58.

4. Ellis M, Manandhar D. Progress in perinatal asphyxia. Semin Neonatol 1999;4(3):183-91.

5. Perlman JM. Interventions strategies for neonatal hypoxicischemic cerebral injury. Clin Ther 2006;28(9):1353-65.

6. Gunn AJ, Gunn TR, Gunning MI, Williams CE, et al Neuroprotection with prolonged head cooling started before postischemic seizures in fetal sheep. Pediatrics 1998;102(5):1098-106.

7. Thoresen M, Wyatt J. Keeping a cool head, posthypoxic hypothermia-an old idea revisited. Acta Paediatr 1997;86(10):1019-33.

8. Gunn AJ. Cerebral hypothermia for prevention of brain injury following perinatal asphyxia. Curr Opin Pediatr 2000;12(2):111-5.
9. Edwards AD, Azzopardi DV. Therapeutic hypothermia following perinatal asphyxia. Arch Dis Child Fetal Neonatal Ed 2006;91(2):F127-31

10. Schulzke SM, Rao S, Patole SK. A systematic review of cooling for neuroprotection in neonates with hypoxic ischemic encephalopathy- are we there yet? BMC Pediatr 2007;7:30.

11. Shah PS, Ohlsson A, Perlman M. Hypothermia to treat neonatal hypoxic ischemic encephalopathy: systematic review. Arch Pediatr Adolesc Med 2007;161(10):951-8.

12. Jacobs S, Hunt R, Tarnow-Mordi W, Inder T, et al Cooling for newborns with hypoxic ischaemic encephalopathy. Cochrane Database Syst Rev 2007;(4):CD00311.

13. García-Alix A, González de Dios J. La encefalopatía hipóxico-isquémica en el recién nacido a término ha dejado de ser una entidad huérfana. Implicaciones para la práctica y necesidad de un "código hipotermia". Evid Pediatr 2010;6(2):27. 